\title{
Detection of Wolbachia pipientis, including a new strain containing the wsp gene, in two sister species of Paraphlebotomus sandflies, potential vectors of zoonotic cutaneous leishmaniasis
}

\author{
Parviz Parvizi ${ }^{1 /+}$, Ali Bordbar ${ }^{1}$, Narmin Najafzadeh ${ }^{1,2}$ \\ ${ }^{1}$ Molecular Systematics Laboratory, Parasitology Department, Pasteur Institute of Iran, Tehran, Iran \\ ${ }^{2}$ Department of Microbiology, Science and Research Branch of Fars, Islamic Azad University, Tehran, Iran
}

\begin{abstract}
Individual, naturally occurring Phlebotomus mongolensis and Phlebotomus caucasicus from Iran were screened for infections with the maternally inherited intracellular Rickettsia-like bacterium Wolbachia pipientis via targeting a major surface protein gene (wsp). The main objective of this study was to determine if $\mathrm{W}$. pipientis could be detected in these species. The sandflies were screened using polymerase chain reaction to amplify a fragment of the Wolbachia surface protein gene. The obtained sequences were edited and aligned with database sequences to identify W. pipientis haplotypes. Two strains of Wolbachia were found. Strain Turk 54 (accession EU780683) is widespread and has previously been reported in Phlebotomus papatasi and other insects. Strain Turk 07 (accession KC576916) is a novel strain, found for first time in the two sister species. A-group strains of W. pipientis occur throughout much of the habitat of these sandflies. It is possible that Wolbachia is transferred via horizontal transmission. Horizontal transfer could shed light on sandfly control because Wolbachia is believed to drive a deleterious gene into sandflies that reduces their natural population density. With regard to our findings in this study, we can conclude that one species of sandfly can be infected with different Wolbachia strains and that different species of sandflies can be infected with a common strain.
\end{abstract}

Key words: Wolbachia pipientis - wsp gene - Paraphlebotomus - L. major - Iran

The prevalence of zoonotic cutaneous leishmaniasis (ZCL), caused by Leishmania major, is increasing in many parts of Iran. ZCL originates as a disease of gerbils and Leishmania parasites are transmitted by sandflies that live and breed in gerbil burrows (Mohebali et al. 2004, Mirzaei et al. 2011). This form of leishmaniasis is of great public health importance in rural areas of 15 out of 32 provinces of Iran (Yaghoobi-Ershadi et al. 2005, Parvizi et al. 2010a). The disease is generally restricted to areas that are heavily infested by sandflies, which are the vectors of ZCL. The Turkmen Sahara region is one of the known focal areas of ZCL in Iran and includes two important ZCL foci (Gonbad Kavous and Maraveh Tapeh) in rural areas. Phlebotomus papatasi (Diptera: Psychodidae) is the main vector and Paraphlebotomus species (Paraphlebotomus mongolensis and Paraphlebotomus caucasicus) are secondary principal vectors of ZCL in this district (Nadim \& Faghih 1968, YaghoobiErshadi et al. 1996, Parvizi \& Ready 2008).

Wolbachia pipientis is a maternally inherited endoparasitic bacterium belonging to the $\alpha$-proteobacteria family that infects $20-75 \%$ of all insect species, including sandflies (Werren et al. 1995, 2008, West et al. 1998,

doi: 10.1590/0074-0276108042013004

Financial support: Pasteur Institute of Iran (367) (to PP)

+ Corresponding author: parp@pasteur.ac.ir

Received 6 September 2012

Accepted 24 January 2013
Jeyaprakash \& Hoy 2000, Werren \& Windsor 2000, Hilgenboecker et al. 2008, Azpurua et al. 2010).

This bacterium has attracted attention because it induces a number of intriguing abnormalities in the host's reproductive system (O'Neill et al. 1997, Stouthamer et al. 1999). These intracellular microorganisms affect the biology of their invertebrate hosts in many ways, ranging from mutualistic effects to the establishment of reproductive isolation and thus, speciation (Werren 1997, Bordenstein et al. 2001, Telschow et al. 2005, Werren et al. 2008).

A wide range of phenotypes are expressed under $W$. pipientis infection, associated with processes ranging from evolution to speciation (Breeuwer \& Werren 1990, Hurst \& Schilthuizen 1998) to mechanisms involved in the genetic modification and biological control of pest arthropods (Sinkins et al. 1997, Bourtzis \& O’Neill 1998), but these bacteria are commonly considered to be reproductive parasites (Moran et al. 2008, Werren et al. 2008).

It is has been noted that most Wolbachia-induced phenotypes increase the proportion of females among the offspring of infected females and pose unique threats to host populations (Werren et al. 2008).

The phenotypes associated with these threats include (i) induction of parthenogenesis in the host, (ii) transformation of males into functional daughters (feminisation), (iii) provoking the selective abortion of sons of infected mothers (male killing) and (iv) cytoplasmic incompatibility (CI), which is the most common phenotype occurring in the mosquito (Hoffmann \& Turelli 1997, Werren et al. 2008). The reproductive distortions caused by Wolbachia infection are known to result in embryonic death and subsequent egg hatching failure due to disruptions during 
the early events of fertilisation. Thus, a Wolbachia strain can promote its rapid vertical transmission throughout a population of the Phlebotomus genus (Benlarbi \& Ready 2003). Wolbachia are vertically transmitted from mothers to daughters, but can occasionally be horizontally transmitted between individuals, including individuals belonging to different species (Pascal et al. 2006).

Wolbachia display tropism for the reproductive tissue of their hosts and are transmitted vertically from insect to insect through the ovules. Interspecific transmission appears to occur horizontally, with the possible aid of parasitoids (Stouthamer et al. 1999, Charlat et al. 2002, Kondo et al. 2002, Ahrens \& Shoemaker 2005, Baldo et al. 2005, Espino et al. 2009).

The Wolbachia surface protein ( $w s p)$ is commonly used as a marker for strain typing (Schaub et al. 1989, Van Meer et al. 1999, Pintureau et al. 2000, Shoemaker et al. 2002, Kyei-Poku et al. 2005) (Fig. 1) and a strain typing system utilising $w s p$ has been developed (Zhou et al. 1998).

The $w s p$ gene is analogous to the antigens employed for serotyping pathogenic bacteria (Stouthamer et al. 1999, Baldo et al. 2006). It is approximately 10 times more variable in its DNA sequence than 16S rRNA (Zhou et al. 1998).

Traditionally, Wolbachia spp detected in arthropods have been divided in two groups (A and B) based on the sequences of their $16 \mathrm{~S}$ rRNA, fts $Z$ and $w s p$ genes (Werren et al. 1995, Zhou et al. 1998). Both groups contain Wolbachia spp that have been detected in several genera of sandflies. Group A includes the Wolbachia spp detected in Sergentomyia and from Phlebotomus. Group B contains the Wolbachia spp detected in sandflies belonging to the Phlebotomus and Lutzomyia genera (Werren et al. 1995, Zhou et al. 1998, Ono et al. 2001).

These bacteria have been detected using molecular tools and reported as "Wolbachia species" from both arthropod and nematode hosts and only a single species has thus far been properly isolated and bears a valid name, $W$. pipientis (Lo et al. 2002).

Wolbachia may have an influential effect on the control of disease vectors based on its potential role in reducing the ability of the host to reproduce, thus decreasing its population size (Beard et al. 1993). Therefore, it is worthwhile to investigate the occurrence and distribution of Wolbachia in sandflies in nature.

The first objective of this study was to determine if $W$. pipientis could be detected in two sister species of Paraphlebotomus sandflies in which the bacterium has not been previously reported. In these two sandfly spe-

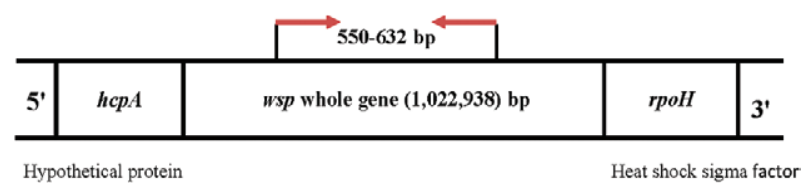

Fig. 1: schematic presentation of the Wolbachia surface protein (wsp) gene, an appropriate candidate as an antigenic serotyping for strain typing of pathogenic bacteria of Wolbachia. cies, P. mongolensis and P. caucasicus, the external genitalia of males provide the only diagnostic morphological characteristics. The females of these sister species cannot be separated morphologically or molecularly based on the structure of the spermathecae, the weakly developed pharyngeal armature or the mitochondrial cytochrome $b$ gene (Theodor \& Mesghali 1964, KillickKendrick 1999, Esseghir et al. 2000, Parvizi et al. 2010a, b). The second objective of this study was to improve our knowledge regarding the detection of one or more strains of $W$. pipientis in one or both sister species of sandfly. Its third objective was to determine if sandflies can be simultaneously infected by two different strains of $W$. pipientis. Finally, the fourth objective of this study was to demonstrate the presence of Wolbachia in Paraphlebotomus sandflies, which would have a significant impact in assessing the diversity of Wolbachia strains, particularly in L. major vectors.

\section{MATERIALS AND METHODS}

Origin and identification of sandflies - The Turkmen Sahara villages in northeastern Iran are a focus of ZCL, where $L$. major parasites are the major causative agent of ZCL. Two sister Paraphlebotomus species were collected regularly from 18 villages of Gonbad Kavous and Maraveh Tapeh in late June and the middle of September in 2008 and 2009. There were also collections performed in September 2010 during peak sandfly activity in the transmission seasons of two successive years (Table I). Additionally, sticky paper and CDC traps were used to sample sandflies in the ruins of mud-walled outhouses adjacent to animal shelters, around houses, at the entrance of gerbil burrows and in houses surrounded by gerbil burrows at the edge of rural areas.

The specimens were identified as $P$. mongolensis males, $P$. caucasicus males or $P$. mongolensis/P. caucasicus females, based on morphological characters of the head and the abdominal terminalia (Lewis 1982).

DNA extraction, gene amplification and sequencing - DNA was extracted from the thorax and attached anterior abdomen of each sandfly. The samples were screened for the presence of $W$. pipientis using the general (or nonstrain specific) primer pair wsp 81F and 691R (Zhou et al. 1998) (Fig 1). Polymerase chain reaction (PCR) amplification was carried out according to the protocol of Benlarbi and Ready (2003).

Each $20 \mu \mathrm{L}$ PCR mixture consisted of 1X Promega buffer B, $25 \mathrm{mM} \mathrm{MgCl}_{2}, 200 \mu \mathrm{M}$ each dNTP, $0.4 \mu \mathrm{M}$ each primer, one unit of Taq DNA polymerase (Promega) and $2 \mu \mathrm{L}$ of sandfly genomic DNA. PCR amplification was carried out as follows: 2 min denaturation at $94^{\circ} \mathrm{C}$, followed by 35 cycles of denaturation at $94^{\circ} \mathrm{C}$ for $30 \mathrm{sec}$, annealing at $50^{\circ} \mathrm{C}$ for $30 \mathrm{sec}$ and extension at $72^{\circ} \mathrm{C}$ for 1 min $30 \mathrm{sec}$, with a final extension at $72^{\circ} \mathrm{C}$ for $10 \mathrm{~min}$.

Following amplification, the samples were fractionated via horizontal submerged gel electrophoresis using $1.5 \%$ agarose gels with DNA size markers (Promega PCR markers G316A or Bioline Hyperladder IV). The obtained DNA fragments were visualised by ethidium bromide staining and then excised and purified using 
the Geneclean II Kit (BIO 101 Inc), prior to sequencing each strand (Testa et al. 2002). The sequences were then edited and aligned with database sequences using Sequencher ${ }^{\mathrm{TM}}$ version 4.4 software (Gene Codes Corp) to identify unique sequences (= haplotypes), which were analysed phylogenetically using MEGA software.

\section{RESULTS}

P. mongolensis and P. caucasicus were identified based on morphological characteristics of their external genitalia. A total of 203 P. mongolensis and P. caucasicus sandflies were trapped at two sites in Turkmen Sahara in the province of Golestan.

The wild sandflies were identified as belonging to two sister species of the Paraphlebotomus subgenus. In total, 74 out of the 203 sandflies examined were infected with Wolbachia. The Wolbachia wsp gene was detected for the first time in all three groups and was distributed as follows: in 33/96 males of $P$. mongolensis, $10 / 15$ males of $P$. caucasicus and 31/92 females of $P$. mongolensis/ $P$. caucasicus (31/92), corresponding to infection rates of $34.37 \%, 66.66 \%$ and $33.69 \%$, respectively (Table I).

We attempted sequencing in all 74 sandflies with Wolbachia infections. However, only 25 of the sandflies presented sufficient DNA for sequencing and/or showed readable sequences demonstrating the presence of $\mathrm{Wol}$ bachia strains.

Two strains of Wolbachia were found in P. mongolensis and P. caucasicus sandflies (Fig. 2). The common strain, Turk 54 (accession EU780683) and a novel strain, Turk 07 (accession KC576916), were found for first time in P. mongolensis and P. caucasicus sandflies from
Turkmen Sahara. Following phylogenetic analyses, these strains appeared to belong to the A-group. A total of 19 of the P. mongolensis and P. caucasicus sandflies exhibited the Turk 54 strain haplotype, while six of the sandflies were infected with strain Turk 07 (Fig. 3, Table II).

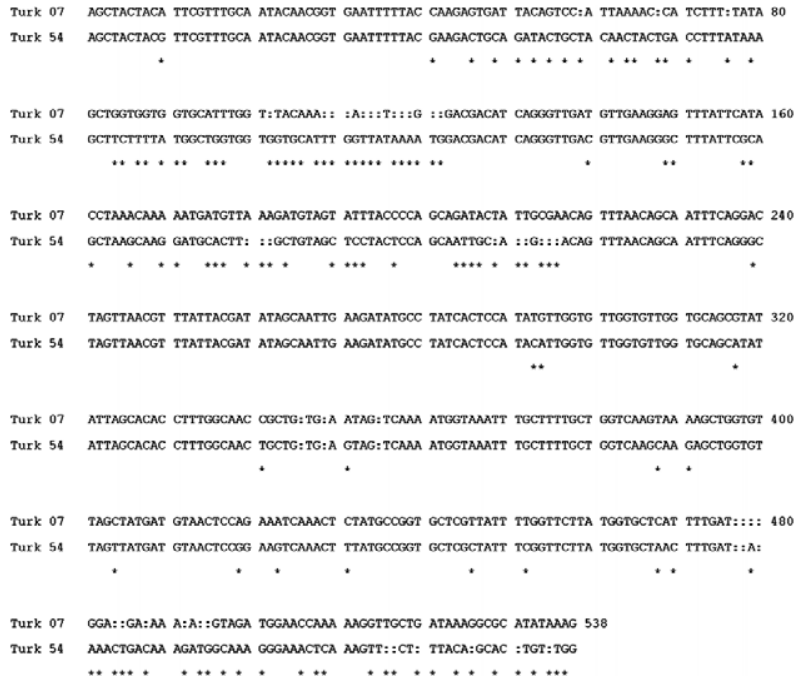

Fig. 2: alignments of the two Wolbachia surface protein gene sequence of Wolbachia pipientis isolated from Iranian sandflies strain Turk 54 isolated first from Phlebotomus papatasi and then most different sandfly species with the GenBank sequence EU780683, Turk 07 isolated from Paraphlebotomus mongolensis and Paraphlebotomus cacusicus. Nucleotide differences are marked by a star.

\section{TABLE I}

Paraphlebotomus caucasicus and Paraphlebotomus mongolensis detected Wolbachia surface protein (wsp) gene in different villages in two locations, Turkmen Sahara, Iran

\begin{tabular}{|c|c|c|c|c|c|c|c|c|c|c|c|c|c|c|c|c|c|}
\hline \multirow[b]{2}{*}{ 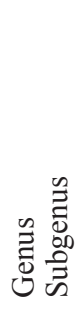 } & \multicolumn{2}{|l|}{ Location } & \multicolumn{7}{|c|}{ Gonbad Kavous } & \multicolumn{6}{|c|}{ Maraveh Tapeh } & \multirow[b]{2}{*}{$\begin{array}{c}\text { Total } w s p \text { gene } \\
\text { Ve per species } \\
\text { n }(\%)\end{array}$} & \multirow[b]{2}{*}{$\begin{array}{c}\text { Total wsp gene } \\
+\mathrm{Ve} \\
\mathrm{n}(\%)\end{array}$} \\
\hline & Species & $\begin{array}{l}0 \\
0 \\
\stackrel{\Xi}{\Xi} \\
\vdots\end{array}$ & 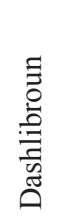 & 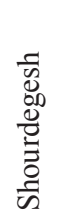 & 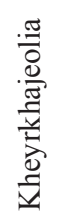 & $\begin{array}{l}\Xi \\
0 \\
0 \\
0 \\
0 \\
\Xi \\
\Xi\end{array}$ & 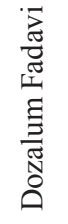 & 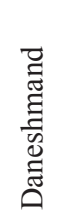 & 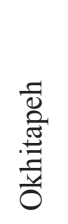 & 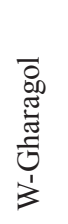 & 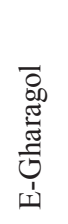 & 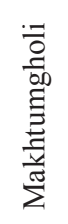 & 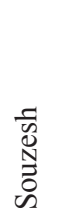 & $\begin{array}{l}: \bar{z} \\
\frac{\pi}{\pi} \\
\frac{\pi}{\pi} \\
\frac{\pi}{\pi}\end{array}$ & 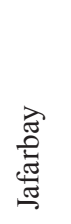 & & \\
\hline \multirow{3}{*}{ 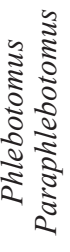 } & P. mongolensis & M) & 4 & 3 & 1 & 2 & 1 & 15 & 4 & 0 & 0 & 1 & 1 & 0 & 1 & $33 / 96$ (34.37) & $33 / 203(16.26)$ \\
\hline & P. caucasicus & M) & 2 & 0 & 0 & 1 & 1 & 2 & 2 & 0 & 0 & 1 & 0 & 1 & 0 & $10 / 15(66.66)$ & $10 / 203(4.92)$ \\
\hline & $\begin{array}{l}\text { P. mongolensis } \\
\text { P. caucasicus }\end{array}$ & $\begin{array}{l}\text { and } \\
\text { F) }\end{array}$ & 6 & 2 & 2 & 5 & 1 & 2 & 1 & 2 & 1 & 2 & 3 & 1 & 3 & 31/92 (33.69) & $31 / 203(15.27)$ \\
\hline Total & & & 12 & 5 & 3 & 8 & 3 & 19 & 7 & 2 & 1 & 4 & 4 & 2 & 4 & \multicolumn{2}{|c|}{$74 / 203$} \\
\hline \multirow[t]{2}{*}{$(\%)$} & & & 5.91 & 2.46 & 1.48 & 3.94 & 1.48 & 9.35 & 3.45 & 0.99 & 0.49 & 1.97 & 1.97 & 0.99 & 1.97 & \multirow{2}{*}{\multicolumn{2}{|c|}{ (36.45) }} \\
\hline & & & & & & 28.08 & & & & & & 0. & & & & & \\
\hline
\end{tabular}

F: female; M: male; +Ve: Wolbachia positive. 
All of the wsp gene fragments amplified from $P$. mongolensis and P. caucasicus were sequenced directly. The 564-bp Turk 54 haplotype (minus primers) (GenBank accession EU780683) was indistinguishable from that of the A-group strain of $W$. pipientis (wPap), which was previously isolated from $P$. papatasi originating from Israel/West Bank (AF237883) (Ono et al. 2001), India (GenBank accession AF237882) (Ono et al. 2001), Spain and Iran (Benlarbi \& Ready 2003, Parvizi et al. 2003). All of these sandflies from Spain and Iran were wild caught, as was the pool of sandflies possessing the AF237883 sequence. The other sequences were isolated from P. papatasi bred in laboratory colonies. Using the same wsp gene primers, Cui et al. (1999) amplified a fragment of approximately $600 \mathrm{bp}$ from a colony of $P$. papatasi originating from Israel/West Bank, North Sinai in Egypt and Saudi Arabia. However, these authors did not report any sequence data. Haplotype wPap was originally reported as presenting an ambiguous base $(\mathrm{C} / \mathrm{T})$ at nucleotide position 102 (GenBank accession AF020082) (Zhou et al. 1998).

The new Turk 07 haplotype differed in a number of point mutations and insertion-deletion events from the previously described haplotypes (Fig 2, Table II). The new sequence was aligned with the available wsp sequences of Wolbachia from sandflies and other insects and phylogenetic relationships were inferred. The

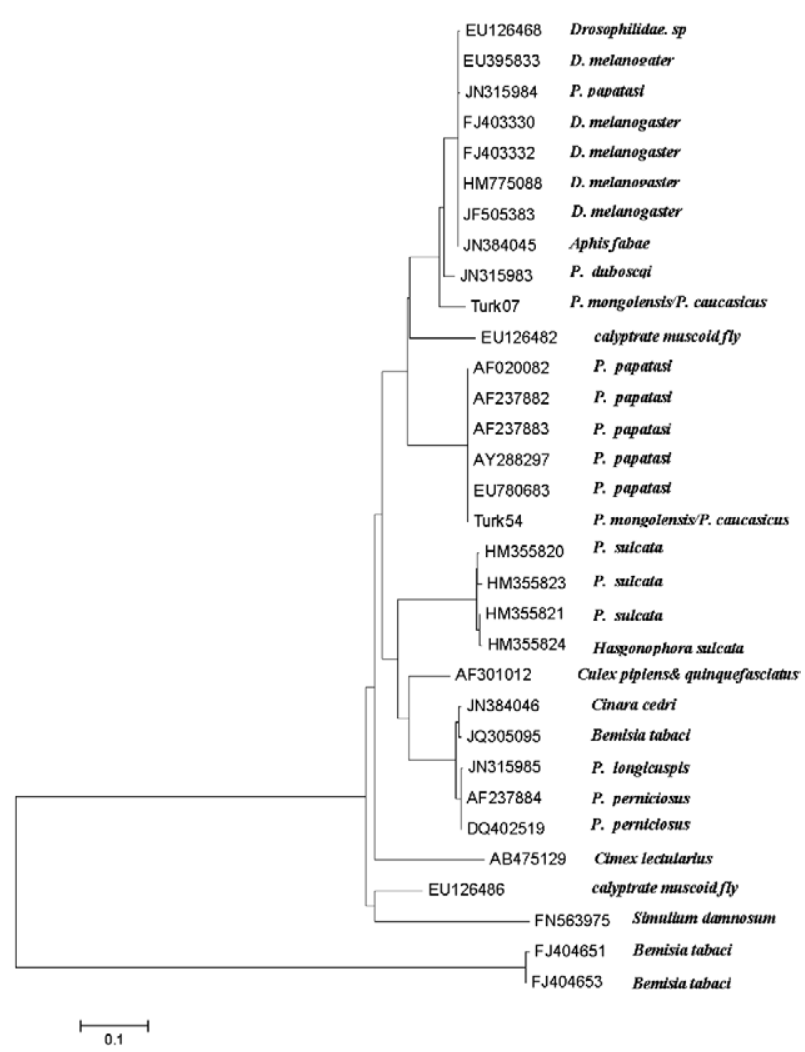

Fig. 3: unrooted neighbour-joining tree showing the relationships of the haplotypes of the Wolbachia surface protein gene fragment for the isolates of Wolbachia listed in Table II. phylogram generated via neighbour-joining analysis placed the sequences from P. papatasi on the same terminal branch within the A-group of strains of $W$. pipientis (Fig. 3).

\section{DISCUSSION}

Here, we report the detection of Wolbachia in two potential vectors of ZCL ( $P$. mongolensis and P. caucasicus) for the first time. Wolbachia had previously been isolated from various insects including sandflies, but infection of $P$. mongolensis and $P$. caucasicus had not been detected. A new $W$. pipientis strain (Turk 07) was found in both $P$. mongolensis and P. caucasicus. Additionally, the widespread common strain (Turk 54) was found in these two sister species.

The infection of the two Paraphlebotomus species with the same strain of Wolbachia may have been due to recent horizontal transmission of Wolbachia across host species. Alternatively, in the case of the closely related species $P$. mongolensis and $P$. caucasicus, infection may be due to co-divergence and co-evolution of Wolbachia strains and their hosts.

Another intriguing finding of this study was that one Paraphlebotomus species can be infected with different Wolbachia strains.

The wsp gene was used for phylogenetic analysis of the Wolbachia strains from which the sequences originated based on a previous study that detected Wolbachia in sandflies with the wsp gene (Werren et al. 1995, Zhou et al. 1998, Ono et al. 2001, Wu \& Hoy 2012).

The wsp sequences obtained from the $P$. mongolensis and $P$. caucasicus Turk 54 strains showed a high similarity to sequences deposited in GenBank as "incompatibility symbiont of $P$. papatasi" (Fig. 3, Table II).

However, the Turk 54 haplotype wsp sequences isolated from Paraphlebotomus were identical to a sequence previously reported from $P$. papatasi from Tunisia and Iran (Benlarbi \& Ready 2003). In contrast, the Turk 07 sequences obtained from $P$. mongolensis and $P$. caucasicus were unique.

Phylogenetic studies using 16S rDNA have established that strains of $W$. pipientis from highly divergent hosts form a monophyletic clade related to the Ehrlichia assemblage within the $\alpha$-subdivision of proteobacteria (O'Neill et al. 1992, Rousset \& Solignac 1995). The examination of $16 \mathrm{~S}$ rDNA sequences is a conservative approach that has allowed not only the phylogenetic placement of bacterial species, but also the phylogenetic resolution of $W$. pipientis into two strain groups: A and B (O’Neill et al. 1992). More recently, the more rapidly evolving wsp gene has been used to improve the phylogenetic resolution within the $W$. pipientis species clade, which was divided into four groups (A-D) and 12 subgroups (Zhou et al. 1998, Ono et al. 2001). The A and $\mathrm{B}$ groups are consistent with those identified via $16 \mathrm{~S}$ rDNA for $W$. pipientis strains from insects, mites and crustaceans, whereas groups $\mathrm{C}$ and $\mathrm{D}$ are consistent with the strains from filarial nematodes.

Wolbachia is normally maintained in nature through vertical transmission (Werren 1997). Although horizontal transfer appears to be infrequent within host populations, it has previously occurred between two host sisters 
species. This demonstrates that the phylogeny of Wolbachia strains differs noticeably from that of their hosts (O’Neill et al. 1992, Werren et al. 1995). This conclusion is supported by experiments revealing the transfer of symbionts between host individuals (Huigens et al. 2000).

The demonstrated horizontal transmission of Wolbachia could shed light on sandfly control because Wolbachia is believed to drive a deleterious gene into mosquitoes that reduce their natural population density (Beard et al. 1993, Sinkins et al. 1997).
The results of a detailed phylogenetic analysis including characterisation of the limitations of such an approach could serve as a foundation for understanding the evolution of Wolbachia bacteria.

Because genetically similar strains are often found in similar insect hosts, ecological interactions among hosts may mediate horizontal transfers. In particular, it appears that the horizontal transmission of Wolbachia has occurred quite recently and frequently within the genus Phlebotomus.

TABLE II

Wolbachia strains isolated from different hosts in various geographical origins and Iran

\begin{tabular}{|c|c|c|c|c|}
\hline Host & Strain & $\begin{array}{l}\text { Geographic } \\
\text { origin }\end{array}$ & $\begin{array}{l}\text { GenBank } \\
\text { accession }\end{array}$ & $\begin{array}{l}\text { Wolbachia surface } \\
\text { protein gene } \\
\text { fragment } \\
\text { (bp) }\end{array}$ \\
\hline Drosophilidae sp. & A_PanPNM_Drosol $2 b$ & Panama & EU126468 & 513 \\
\hline Drosophila melanogaster & $w M e l$ & China & EU395833 & 632 \\
\hline Phlebotomus papatasi & wPhleb3lf & France & JN315984 & 568 \\
\hline D. melanogaster & wMel & Wuhan & FJ403330 & 638 \\
\hline D. melanogaster & $w M e l$ & Yunnan & FJ403332 & 637 \\
\hline D. melanogaster & - & Ukraine & HM775088 & 600 \\
\hline D. melanogaster & - & India & JF505383 & 590 \\
\hline Aphis fabae & wsp_GRA4 & Greece & JN384045 & 620 \\
\hline Phlebotomus duboscqi & wPhlebM4 & France & JN315983 & 524 \\
\hline $\begin{array}{l}\text { Paraphlebotomus mongolensis } \\
\text { Paraphlebotomus caucasicus }\end{array}$ & (Turk 07) & Iran & КC576916 & 551 \\
\hline Calyptrate muscoid fly & A_MexSon_Calyp150671 & Mexico & EU126482 & 486 \\
\hline P. papatasi & Wpap & Israel & AF020082 & 564 \\
\hline P. papatasi & $w P a p$ & India & AF237882 & 563 \\
\hline P. papatasi & $w P a p$ & Israel & AF237883 & 563 \\
\hline P. papatasi & - & Egypt & AY288297 & 561 \\
\hline $\begin{array}{l}\text { P. papatasi } \\
\text { P. mongolensis } \\
\text { P. caucasicus }\end{array}$ & $\begin{array}{c}\text { papa01 } \\
\text { (Turk 54) }\end{array}$ & Tunisia/Iran & EU780683 & 563 \\
\hline Phasgonophora sulcata & - & Canada & HM355820 & 596 \\
\hline P. sulcata & - & Canada & HM355823 & 596 \\
\hline P. sulcata & - & Canada & HM355821 & 596 \\
\hline Hasgonophora sulcata & - & Canada & HM355824 & 596 \\
\hline Culex pipiens quinquefasciatus & Wpip & United States of America & AF301012 & 558 \\
\hline Cinara cedri & wsp_BS_Salamanca $(\mathrm{CCeS})$ & Spain & JN384046 & 585 \\
\hline Bemisia tabaci & & Bangladesh & JQ305095 & 490 \\
\hline Phlebotomus longicuspis & wPhleb54d & France & JN315985 & 517 \\
\hline P. perniciosus & $w \operatorname{Prn}$ & Italy & AF237884 & 554 \\
\hline P. perniciosus & - & France & DQ402519 & 510 \\
\hline Cimex lectularius & $T I H$ & Japan & AB475129 & 562 \\
\hline Calyptrate muscoid fly & A_NY_Calyp150743b & United States of America & EU126486 & 501 \\
\hline Simulium damnosum & - & Ghana & FN563975 & 565 \\
\hline Bemisia tabaci & $w B t a b$ ch 2 & China & FJ404651 & 601 \\
\hline B. tabaci & wBtab ch 4 & China & FJ404653 & 607 \\
\hline
\end{tabular}


Wolbachia is also interesting in an evolutionary context due to the diversity and elegance of its interactions with its hosts and because the barriers to cross crossmating between populations may reinforce the genetic divergence between them or speciation (Laven 1967, Bordenstein 2003).

The presence of $W$. pipientis is not strictly associated with ZCL endemicity, as this bacterium has been found in populations of $P$. papatasi from non-endemic areas of Iran (Parvizi et al. 2003).

Independent of their mitochondrial haplotype, geographical origin and habitat, wild $P$. papatasi have been found to be either uninfected with $W$. pipientis or infected with one common widespread strain. This raises the possibility of using a genetically modified strain of $W$. pipientis to drive transgenes through wild sandfly populations to intervene in the transmission of Leishmania.

$\mathrm{CI}$ is a recognised phenotype caused by natural Wolbachia infection in sandflies. It is believed that Wolbachia might prevent the transmission of virus and parasite infections (Dobson et al. 2002).

Until now, it was believed that individual strains of Wolbachia could only be assigned to a particular species of sandfly. However, in the present study, it has been shown that one species of sandfly can be infected with different Wolbachia strains and that different species of sandflies can be infected either with a common haplotype or common strain. While Wolbachia strains were also found in two species of the Paraphlebotomus subgenus for the first time in the present study, the first two observations are more significant. The wsp gene is a very useful tool for typing different Wolbachia strains. The frequent incidence of Wolbachia strains and their ability to manipulate host reproduction has led to Wolbachia being proposed as important agents in the evolution of arthropod hosts. Wolbachia provides a starting point for inducing changes in host sex or sexuality. By manipulating Wolbachia via transgenes, it is hoped that these bacteria may be able to be used as a system to decrease vector-borne-diseases and to reduce the transmission of diseases in the future. As a main vector of $L$. major, these bacteria can be employed as a gene-driving system for spreading anti-pathogen transgenes through wild populations of sandflies.

The infection rates of Wolbachia among the observed Iranian populations of $P$. mongolensis and $P$. caucasicus were low and the reason for such low infection rates could be that there are different densities of the infecting bacteria in different locations. The low detection rates of Wolbachia in $P$. caucasicus males in comparison with $P$. mongolensis males and the females of both species can be explained by the fact that most of the $P$. mongolensis males and the females of both species were caught in gerbil burrows. Therefore, it is possible that Wolbachia might be spread by transgenes in gerbil burrows.

Further studies examining Wolbachia species in sandflies are needed to reveal the relationship between Wolbachia endosymbionts and phlebotomine hosts.

\section{ACKNOWLEDGEMENTS}

To Mehdi Baghban, for helping with the field working, and to Elnaz Alaee Novin, for helping in Molecular Systematics Laboratory.

\section{REFERENCES}

Ahrens M, Shoemaker D 2005. Evolutionary history of Wolbachia infections in the fire ant Solenopsis invicta. BMC Evol Biol 5: 35.

Azpurua J, de la Cruz D, Valderama A, Windsor D 2010. Lutzomyia sand fly diversity and rates of infection by Wolbachia and an Exotic Leishmania species on Barro Colorado Island, Panama. PLoS Negl Trop Dis 4: e627.

Baldo L, Dunning HJC, Jolley KA, Bordenstein SR, Biber SA, Choudhury RR, Hayashi C, Maiden MC, Tettelin H, Werren JH 2006. Multilocus sequence typing system for the endosymbiont Wolbachia pipientis. Appl Environ Microbiol 72: 7098-7110.

Baldo L, Lo N, Werren J 2005. Mosaic nature of the Wolbachia surface protein. J Bacteriol 187: 5406-5418.

Beard CB, O’Neill SL, Tesh RB, Richards FF, Aksoy S 1993. Modification of arthropod vector competence via symbiotic bacteria. Parasitol Today 9: 179-183.

Benlarbi M, Ready PD 2003. Host-specific Wolbachia strains in widespread populations of Phlebotomus perniciosus and P. papatasi (Diptera: Psychodidae) and prospects for driving genes into these vectors of Leishmania. Bull Entomol Res 93: 383-391.

Bordenstein SR 2003. Symbiosis and the origin of species. In K Bourtzis, T Miller, Insect symbiosis, CRC Press, New York, 320 pp.

Bordenstein SR, O’Hara FP, Werren JH 2001. Wolbachia-induced incompatibility precedes other hybrid incompatibilities in Nasonia. Nature 409: 707-710.

Bourtzis K, O’Neill SL 1998. Wolbachia infection and arthropod reproduction. Bioscience 48: 287-293.

Breeuwer JA, Werren JH 1990. Microorganisms associated with chromosome destruction and reproductive isolation between two insect species. Nature 346: 558-560.

Charlat S, Nirgianaki A, Bourtzis K, Mercot H 2002. Evolution of Wolbachia-induced cytoplasmic incompatibility in Drosophila simulans and D. sechellia. Evolution 56: 1735-1742.

Cui W, Zhang SN, Chen W, Morgan EH 1999. Strong aperiodic Xray variability and quasi-periodic oscillationin x-ray Nova XTE J1550-564. Astro J Lett 512: 1-12.

Dobson SL, Fox CW, Jiggins FM 2002. The effect of Wolbachiainduced cytoplasmic incompatibility on host population size in natural and manipulated systems. Proc Biol Sci 269: 437-445.

Espino CI, Gómez T, González G, Brazil do Santos MF, Solano J, Sousa O, Moreno N, Windsor D, Ying A, Vilchez S, Osuna A 2009. Detection of Wolbachia bacteria in multiple organs and feces of the triatomine insect Rhodnius pallescens (Hemiptera, Reduviidae). Appl Environ Microbiol 75: 547-550.

Esseghir S, Ready PD, Ben-Ismail R 2000. Speciation of Phlebotomus sandflies of the subgenus Larroussius coincided with the late Miocene-Pliocene aridification of the Mediterranean subregion. Biol J Linn Soc Lond 70: 189-219.

Hilgenboecker K, Hammerstein P, Schlattmann P, Telschow A, Werren JH 2008. How many species are infected with Wolbachia? A statistical analysis of current data. FEMS Microbiol Lett 281: 215-220.

Hoffmann AA, Turelli M 1997. Cytoplasmic incompatibility in insects. In SL O'Neill, AA Hoffman, JH Werren (eds.), Influential passengers: microbes and arthropod reproduction, Oxford University Press, Oxford, p. 42-80.

Huigens ME, Luck RF, Klaassen RHG, Maas MFPM, Timmermans MJTN, Stouthamer R 2000. Infectious parthenogenesis. Nature 6782: 178-179.

Hurst GDD, Schilthuizen M 1998. Selfish genetic elements and speciation. Heredity 80: 2-8. 
Jeyaprakash A, Hoy M 2000. Long PCR improves Wolbachia DNA amplification wsp sequences found in $76 \%$ of sixty-three arthropod species. Insect Mol Biol 9: 393-405.

Killick-Kendrick R 1999. The biology and control of phlebotomine sand flies. Clin Dermatol 17: 279-289.

Kondo N, Nikoh N, Ijichi N, Shimada M, Fukatsu T 2002. Genome fragment of Wolbachia endosymbiont transferred to X chromosome of host insect. Proc Natl Acad Sci USA 99: 14280-14285.

Kyei-Poku GK, Colwell DD, Coghlin P, Benkel B, Floate KD 2005. On the ubiquity and phylogeny of Wolbachia in lice. Mol Ecol 14: $285-294$.

Laven H 1967. Speciation and evolution in Culex pipiens. In R Wright, $\mathrm{R}$ Pal (eds.), Genetic of insect vectors of disease, Elsevier, Amsterdam, p. 251-275.

Lewis DJ 1982. A taxonomic review of the genuse Phlebobtomus. Bull Brit Nat Hist (Entomol) 45: 121-209.

Lo N, Casiraghi M, Salati E, Bazzocchi C, Bandi C 2002. How many Wolbachia supergroups exist? Mol Biol Evol 19: 341-346.

Mirzaei A, Roushani S, Taherkhani H, Farahmand M, Kazemi B, Hedayati M, Baghaei A, Davari B, Parvizi P 2011. Isolation and detection of Leishmania species among naturally infected Rhombomis opimus, a reservoir host of zoonotic cutaneous leishmaniasis in Turkemen Sahara, North East of Iran. Exp Parasitol 129: 375-380.

Mohebali M, Khamesipour A, Mobedi I, Zarei Z, Hashemi-Fesharki $\mathrm{R} 2004$. Double-blind randomized efficacy field trial of alum precipitated autoclaved Leishmania major vaccine mixed with BCG against canine visceral leishmaniasis in Meshkin-Shahr district, I.R. Iran. Vaccine 22: 4097-4100.

Moran NA, McCutcheon JP, Nakabachi A 2008. Genomics and evolution of heritable bacterial symbionts. Annu Rev Genet 42: 165-190.

Nadim A, Faghih M 1968. The epidemiology of cutaneous leishmaniasis in the Isfahan province of Iran. I. The reservoir. II. The human disease. Trans R Soc Trop Med Hyg 61: 534-542.

O'Neill HW, Hoffmann AA, Werren JH 1997. Influential passengers: inherited microorganisms and arthropod reproduction, Oxford University Press, Oxford, 320 pp.

O’Neill SL, Giordano R, Colbert AME, Karr TL, Robertson HM 1992. 16S rRNA phylogenetic analysis of the bacterial endosymbionts associated with cytoplasmic incompatibility in insects. Proc Natl Acad Sci USA 89: 2699-2702.

Ono M, Braig HR, Munstermann LE, Ferro C, O’Neill SL 2001. Wolbachia infections of phlebotomine sand flies (Diptera: Psychodidae). J Med Entomol 38: 237-241.

Parvizi P, Benlarbi M, Ready PD 2003. Mitochondrial and Wolbachia markers for the sandfly Phlebotomus papatasi: little population differentiation between peridomestic sites and gerbil burrows in Isfahan province, Iran. Med Vet Entomol 17: 351-362.

Parvizi P, Naddaf SR, AlaeeNovin E 2010a. Molecular typing and phylogenetic analysis of some species belonging to Phlebotomus (Larroussius) and Phlebotomus (Adlerius) subgenera (Diptera: Psychodidae) from two locations in Iran. Iran J Arthropod Borne Dis 4: 1-10.

Parvizi P, Ready PD 2008. Nested PCRs of nuclear ITS-rDNA fragments detect three Leishmania species of gerbils in sanflies from Iranian foci of zoonotic cutaneous leishmaniasis. Trop Med Int Health 13: 1159-1171.

Parvizi P, Tahehrkhani H, Ready PD 2010b. Phlebotomus caucasicus and Phlebotomus mongolensis (Diptera: Psychodidae): indistinguishable by the mitochondrial cytochrome $b$ gene in Iran. Bull Entomol Res 100: 415-420.

Pascal C, Pintureau B, Katchadourian C, Grenier S, Bolland P, Robin C, Vallier A 2006. Comparison of Wolbachia bacterial density in females of four thelythokous strains of Trichogramma cordubensis and T. evanescens (Hymenoptera, Trichoogrammatidae). Vestn Zool 40: 417-425.

Pintureau B, Chaudier S, Lassabliere F, Charles H, Grenier S 2000. Addition of wsp sequences to the Wolbachia phylogenetic tree and stability of the classification. $J$ Mol Evol 51: 374-377.

Rousset F, Solignac M 1995. Evolution of single and double Wolbachia symbioses during speciation in the Drosophila simulans complex. Proc Natl Acad Sci USA 92: 6389-6393.

Schaub GA, Boker CA, Jensen C, Reduth D 1989. Cannibalism and coprophagy are modes of transmission of Blastocrithidia triatomae (Trypanosomatidae) between triatomines. J Protozool 36: 171-175.

Shoemaker DD, Machado CA, Molbo D, Werren JH, Windsor DM, Herre EA 2002. The distribution of Wolbachia in fig wasps: correlations with host phylogeny, ecology and population structure. Proc R Soc Lond B Biol Sci 269: 2257-2267.

Sinkins SP, Curtis CF, O'Neill SL 1997. The potential application of inheried symbiont systems to pest control. In SL O' Neill, A Hoffman, J Werren (eds.), Influential passengers, Oxford University Press, Oxford, p. 155-175.

Stouthamer R, Breeuwer JAJ, Hurst GDD 1999. Wolbachia pipientis: microbial manipulator of arthropod reproduction. Аnпи Rev Microbiol 53: 71-102.

Telschow A, Hammerstein P, Werren JH 2005. The effect of Wolbachia versus genetic incompatibilities on reinforcement and speciation. Evolution 59: 1607-1619.

Testa JM, Montoya-Lerma J, Cadena H Oviedo M, Ready PD 2002. Molecular identification of vectors of Leishmania in Colombia: mitochondrial introgression in the Lutzomyia townsendi series. Acta Trop 84: 205-218.

Theodor O, Mesghali A 1964. On the Phlebotominae of Iran. $J$ Med Entomol 1: 285-300.

Van Meer MMM, Witteveldt J, Stouthamer R 1999. Phylogeny of the arthropod endosymbiont Wolbachia based on wsp gene. Insect Mol Biol 8: 399-408.

Werren JH 1997. Biology of Wolbachia. Annu Rev Entomol 42: 587609.

Werren JH, Baldo L, Clark ME 2008. Wolbachia: master manipulators of invertebrate biology. Nat Rev Microbiol 6: 741-751.

Werren JH, Guo LR, Zhang W 1995. Evolution and phylogeny of Wolbachia: reproductive parasites of arthropods. Proc R Soc Lond B Biol Sci 251: 55-63.

Werren JH, Windsor DM 2000. Wolbachia infection frequencies in insects: evidence of a global equilibrium? Proc R Soc Lond B Biol Sci 267: 1277-1286.

West SA, Cook JM, Werren JH, Godfray HC 1998. Wolbachia in two insect host-parasitoid communities. Mol Ecol 7: 1457-1465.

Wu K, Hoy MA 2012. Cardinium is associated with reproductive incompatibility in the predatory mite Metaseiulus occidentalis (Acari: Phytoseiidae). J Invertebr Pathol 110: 359-365.

Yaghoobi-Ershadi MR, Akhavan AA, Mohebali M 1996. Meriones libycus and Rhombomys opimus (Rodentia: Gerbillidae) are the main reservoir hosts in a new focus of zoonotic cutaneous leishmaniasis in Iran. Trans R Soc Trop Med Hyg 90: 503-504.

Yaghoobi-Ershadi MR, Zahraei-Ramazani AR, Akhavan AA, JalaliZand AR, Abdoli H, Nadim A 2005. Rodent control operations against zoonotic cutaneous leishmaniasis in rural Iran. Ann Saudi Med 25: 309-312.

Zhou W, Rousset F, O'Neill S 1998. Phylogeny and PCR-based classification of Wolbachia strains using wsp gene sequences. Proc $R$ Soc Lond B Biol Sci 265: 509-515. 